\title{
O PROgRAMA DE INVESTIMENTO EM LOGístiCA (PIL): DIRETRIZES, OBJETIVOS E DESFECHOS
}

Resumo: O Programa de Investimento em Logística (PIL) foi lançado durante a primeira gestão (2011-2014) da Presidenta Dilma Rousseff. O PIL tinha como objetivo ampliar a infraestrutura e a logística referente à movimentação de cargas no Brasil. Entretanto, a produção de conflitivas relações políticas/econômicas/ideológicas no Brasil, entre os anos de 2013 e 2016, influenciou e colocou fim ao que estava previsto. Desta maneira, o objetivo deste artigo é descrever as estratégias, as diretrizes e objetivos do PIL), bem como, demonstrar quais foram os resultados obtidos. Para tal, fizemos uso de levantamento bibliográfico, documental e no ciberespaço.

Palavras-chave: Programa de Investimento em Logística. Parceria Público-Privada. Logística. Transporte. Golpe de 2016.

\section{THE LOGISTICS' INVESTIMENT PROGRAMA (PIL): GUIDELINES, OBJECTIVES AND UPSHOTS}

Abstract: The Logistics' Investment Program (PIL) was launched during the first management (2011-2014) of President Dilma Rousseff. The PIL aimed to increase the infrastructure and logistics related to carrying loads in Brazil. However, the production of political/economic/ideological conflicting relations in Brazil, between the years of 2013 and 2016, influenced and putted end to what was planned. In this way, the objective of this article is to describe the strategies, the guidelines and the objectives of the PIL, as well as to demonstrate the results obtained. For this, we perform bibliographical, documentary and cyberspace surveys.

Keywords: Logistics' Investment Program. Logistics. Public-Private Partnership. Logistics. Transport. Coup of 2016.

\section{EL PROGRAMA DE INVERSIÓN EM LOGISTICA (PIL): DIRETRICES, OBJETIVOS Y RESULTADO}

Resumen: El Programa de Inversión en Logistica (PIL) se lanzó durante la primera gestión (2011-2014) de la Presidenta Dilma Rousseff. El objetivo de la PIL era aumentar la capacidad, la eficiencia, la eficacia y reducir los costos logísticos relacionados con el transporte de cargas en Brasil. Sin embargo, la producción de relaciones políticas/económicas/ideológicas conflictivas en Brasil, entre los años 2013 y 2016, influyó y puso fin a lo planeado. De esta manera, el objetivo de este artículo es describir las estrategias, las directrices y objetivos del PIL), así como, demostrar cuáles fueron los resultados obtenidos. Así, realizamos levantamiento bibliográfico, documental y en el ciberespacio.

Palabras clave: Programa de Inversión en Logistica. Asociación Público-Privada. Logistica. Transporte. Golpe de 2016.

1 Universidade Estadual do Centro-Oeste - UNICENTRO, Programa de Pós-Graduação em Geografia, Guarapuava/PR, Brasil, robertomauro.fernandes@hotmail.com, https://orcid.org/0000- 


\section{Introdução}

No dia 15 de agosto de 2012, a presidenta Dilma Rousseff lançou o Programa de Investimentos em Logística (PIL). Seriam investidos entre 2012 e 2015 cerca de $\mathrm{R} \$ 451,4$ bilhões de reais em recursos públicos para a ampliação da infraestrutura de transportes no Brasil. Ademais, a intenção era que tais investimentos pudessem incentivar o aumento da aplicação de recursos privados e coaduná-los a outros elementos da logística.

Assim, o governo escolheu extinguir a cobrança do valor da outorga nas concessões e ampliar o investimento privado através das mudanças dos preços relativos para induzir as decisões de aplicação (BASTOS, 2017; CARNEIRO, 2017). O PIL também trazia em seu interior o modelo de Parcerias Público-Privadas, regulado pela Lei no 11.079/04, de 30 de dezembro de 2004 (Lei de PPPs). O Governo Dilma ao lançar o PIL optou pelos investimentos via concessão e adotou de forma parcial o investimento público convencional.

Com a publicação do PIL, a intenção era iniciar um processo para corrigir as deficiências no setor de transporte nacional, integrando a malha ferroviária e construindo trechos que em pleno século XXI ainda não existem, interligando tais fixos as rodovias e consequentemente aos portos e aeroportos. Além disso, o Programa tinha como escopo possibilitar o acesso eficiente a grande parte da sociedade brasileira, por exemplo, por meio de um programa de aviação regional, subsidiando passagens e tarifas, na tentativa de mitigar as alternâncias no uso dos modais. Assim como, objetivava criar a um novo marco regulatório para o setor aeroportuário, que alicerçasse uma engenharia de integração entre operadores particulares com a infra e superestrutura pública e vice-versa, desobstruindo os gargalos do setor.

Disto isso, o objetivo deste artigo é descrever as estratégias, as diretrizes e objetivos do Programa de Investimento em Logística (PIL), bem como, demonstrar quais foram os resultados obtidos. É preciso ressaltar que as informações contidas neste texto são uma síntese dos resultados de uma pesquisa realizada entre os anos de 2013 e 2016 que resultou em uma tese de doutorado na área de geografia, defendida em abril de 2017. De igual modo, é necessário apontar que a narrativa será sempre no passado, pois o PIL foi extinto com o Golpe que retirou a presidenta Dilma do Poder Executivo em 2016. 
Para realização deste debate, fizemos uso de levantamento bibliográfico e documental, bem como, apuramos informações no ciberespaço, manuseando as informações dos sites governamentais e notícias divulgadas na imprensa.

No que tange ao levantamento bibliográfico, optamos por uma abordagem em livros, capítulos de livros e artigos na área do direito administrativo. $\mathrm{Na}$ análise documental, recorremos as minutas de editais, contratos de concessão, leis, decretos, portarias. Documentos que foram publicados entre os anos de 2012 e 2015. Tais fontes foram fundamentais para averiguarmos como o PIL estava estruturado, especialmente, pois no período mencionado era escassa (e ainda é) a bibliografia sobre o programa.

Em relação ao ciberespaço, este é o ambiente virtual alicerçado por meio de uma rede de computadores, o espaço de comunicação interconectado pelas memórias dessa rede (LÉVY, 2000, p.92; LEMOS, 2004, p.115) e que possibilita acesso as informações da imprensa mundial. Quando realizamos a pesquisa, o PIL estava em curso, para nos mantermos atualizados acerca dos processos no âmbito nacional, recorríamos ao ciberespaço com acesso a mídia. O contexto político estava agitado (o golpe contra a presidenta Dilma estava sendo preparado), os núcleos responsáveis pelo programa não repassavam informações, por conseguinte, os informes da imprensa passaram a ser importantes. Logo, analisávamos os discursos veiculado e buscávamos a informação nos sites dos órgãos oficiais envolvidos no PIL. Assim, foi possível realizar as comparações entre os documentos oficiais e o discurso midiático com o seu teor político.

\section{A lei no 11.079/2004: a base jurídica para os investimentos do PIL}

O Governo Federal (gestão Dilma Rousseff - 2011/14) ao lançar o Programa de Investimento em Logística optou por investimentos via concessão. Para atingir os objetivos econômicos e políticos do programa e iniciar as ações da primeira etapa (reuniões participativas para tomadas de subsídios técnicos, publicação de editais, leilões e audiências no decorrer do ano de 2013) pôs em prática, em âmbito nacional, a Lei № 11.079/04. A norma regulamenta as chamadas Parcerias PúblicoPrivadas (PPPs). Assim, foi a base jurídica que regulou os critérios de contratação do Poder Público frente a iniciativa privada no interior do PIL. Deste modo, é importante trazer à tona alguns aspectos da instituição.

A lei trata de uma forma de contratação na qual o parceiro público, detentor dos ativos, assume riscos juntamente com o parceiro-privado e the fornece 
garantias. O particular, em contrapartida, executa o serviço com remuneração total ou parcial, sujeitando-se a contraprestação (subsídio) efetuada pelo Poder Público contratante. Os projetos do PIL seriam realizados com uma contraprestação pecuniária do parceiro-público ao parceiro-privado.

Cabe também destacar que lei possibilita a realização de PPPs em áreas cujos projetos são de pouca ou nenhuma viabilidade econômica, como de rodovias, ferrovias, entre outros. Desta maneira, está plasmado na norma que somente os projetos que necessitam do comprometimento de recursos públicos para pagamento ao parceiro privado podem ser classificados como tal (SOARES e CAMPOS NETO, 2006, pp. 13/14). O que era o caso do PIL em todos os setores. Estava previsto no projeto a construção de infraestrutura, além da manutenção de tais equipamentos em regiões com baixo volume de fluxos e menos desenvolvidas do ponto de vista econômico.

A lei possibilitaria ao Poder Público contratar particulares por meio de concessão patrocinada e a concessão administrativa. $\mathrm{Na}$ primeira (que foi diretamente o caso das concessões rodoviárias), além da cobrança tarifária aos usuários haveria a possibilidade de uma complementação de recursos por parte do Poder Público, seria uma contraprestação pública parcial, a lei autoriza que o Estado financie até $70 \%$ das obras com recursos. Na segunda haveria possibilidade de realização de um contrato de prestação de serviços no qual a administração pública seria usuária indireta e direta, desta maneira, ocorreria concessão de serviço público, sendo prestado diretamente ao usuário. Nesse caso, as despesas correntes da parceria são pagas integralmente pelo setor público caso o empreendimento não possa ser subsidiado por meio de tarifas ou pedágios (BINENBOJM, 2005).

Logo, Lei 11.079/04 prevê o estabelecimento, via contrato, de metas de desempenho para o particular - critério entabulado no artigo 6 o da institucionalidade. $\mathrm{O}$ contratado, mediante as metas e exigências, recebe 0 pagamento público (subsídio) de acordo com à eficiência no cumprimento do serviço prestado. Esta especificidade da lei foi regra nos contratos assinados e naqueles que estavam previstos no interior do PIL.

A Lei de PPPs prevê e autoriza a celebração de contratos de concessão por prazos de no mínimo cinco anos e de no máximo trinta e cinco anos, o que pode implicar em investimentos de grande porte e com extenso período de amortização do financiamento realizado por parte das instâncias públicas. Bem como, teoricamente sugere contratações "despartidarizadas", os prazos contratuais 
perpassariam vários mandatos e diferentes governos. As concessões do PIL, em todos os setores, teriam duração de 30 anos.

A norma também estabelece garantias mais efetivas à atração de parceiro privado, segundo a institucionalidade as obrigações pecuniárias contraídas pelo Poder concedente devem ser custeadas por meio de um Fundo Garantidor para Pagamentos das Parcerias Público-Privadas de estatais dependentes autorizadas a participar, no limite global de $\mathrm{R} \$$ 6.000.000.000,00 (BRASIL, 2004). Destarte, é constituído com recursos públicos da União, cujo escopo é garantir os pagamentos futuros assumidos pelo Poder Público em virtude de suas obrigações pecuniárias oriundas da assinatura dos contratos de Parceria Público-Privadas.

Ademais, a 11.079/04 impõe a necessidade de estudos de comparação entre custos e benefícios para que o projeto seja realizado através de Parceria Público-Privada, conhecido como "Valor pelo Dinheiro" ("Value for Money"). Esta análise consiste na comparação entre os custos e os benefícios definidos para um projeto enquadrado como PPP (UNIDADE PPP MINAS GERAIS, 2005, p.12). De acordo com a normativa, o estudo deve ser apresentado antes da publicação do edital, bem como, a União somente poderá contratar Parcerias Público-Privadas com desembolsos anuais para os projetos que não excedam $1 \%$ da receita corrente líquida do exercício anterior (BRASIL, 2004).

O limite supracitado foi imposto aos Estados, Distrito Federal e Municípios, como condição prévia ao recebimento de recursos financeiros e garantias da União para que não ocorra fuga dos limites estabelecidos pela Lei de Responsabilidade Fiscal e, ao mesmo tempo, trata-se de mais um instrumento que tem como objetivo restringir impactos futuros das PPPs sobre as contas públicas.

A norma prescreve no seu artigo $3^{\circ}$, inciso III, a repartição de riscos entre as partes (BRASIL, 2004). Uma necessidade contratual que a lei 8.987/1995 (Lei de concessão comum) não prevê. Nesta, os riscos econômicos decorrentes do empreendimento, são transferidos de maneira integral para o contratado. Nas PPPs, o Poder Concedente e o prestador do serviço dividem os riscos do projeto. Isto era cláusula imutável nos contratos do PIL.

A Lei 11.079/04 também dispõe, no artigo 5ํㅗㅇ sobre a possibilidade de transferência do controle da Sociedade de Propósitos Específicos (SPE) para os financiadores do projeto, caso a concessionária não cumprir com o contrato de parceria. A SPE é um modelo de organização empresarial pelo qual se constitui uma nova empresa para cuidar de determinadas questões relativas a um projeto, possui 
personalidade jurídica, escrituração contábil própria, tem obrigações tributárias, de igual modo, é uma sociedade patrimonial, podendo adquirir bens móveis, imóveis e participações.

Na Lei 11.079/04, artigo 9º a SPE, que deve ser criada antes da celebração dos contratos, fica "[...] incumbida de implantar e gerir o objeto da parceria". Cabe aqui à Administração Pública fixar no contrato de concessão as situações em que ocorrerá essa transferência para o agente financiador (BRASIL, 2004). Entende-se que seria mais adequado a SPE assumir o serviço nos casos de descumprimento do estabelecido (por parte da concessionária), pois possuiria todo o conhecimento contábil da parceria, podendo utilizar a experiência que já possui na gestão para contratar a equipe técnica especializada para então, sob seu controle, dar continuidade ao serviço mal prestado ou interrompido.

Outro ponto interessante na legislação brasileira para PPPs e que consta no artigo $5^{\circ}$, inciso IX, é a possibilidade de "[...] compartilhamento com a Administração Pública de ganhos econômicos efetivos do parceiro privado decorrentes da redução do risco de crédito dos financiamentos utilizados pelo parceiro privado" (BRASIL, 2014). Neste caso, as perspectivas de compartir benefícios econômicos espraiamse, os ganhos podem ser com a redução de risco de créditos (como cita a redação), mas também com menores gastos com juros, com a capitação de lucros oriundos do aumento do volume de usuários do serviço e a consequente ampliação da arrecadação com pedágios e tarifas.

Em suma, estas são algumas das particularidades da institucionalidade que deram sustentação ao modelo de Parcerias Público-Privadas no Brasil. Norma que foi instrumentalizada em nível nacional com o lançamento do Programa de Investimento em Logística cujo objetivo era financiar com projetos estruturantes o setor rodoviário, ferroviário, aeroportuário e portuário.

\section{O Programa de Investimento em Logística: rodovias e ferrovias}

No que se refere ao setor rodoviário, a primeira etapa do PIL marcou a divulgação do repasse à iniciativa privada a responsabilidade de implantação e duplicação de 7,5 mil quilômetros de rodovias. Foram anunciados para este intento $\mathrm{R} \$ 46$ bilhões de reais em investimentos públicos. O modelo publicado previa concessões com prazo de trinta anos. A intenção era que $R \$ 23,5$ bilhões deste montante fossem injetados nos cinco primeiros anos de contrato, contabilizando cerca de 5,7 mil rodovias duplicadas (TV NBR, 2012). 
Assim como, a taxa de retorno alavancada (TRA) anunciada ficou entre 10,8 $\%$ e $14,6 \%$. A TRA diz respeito à remuneração de capital dos investidores privados. Os valores a priori pareciam atrativos, o problema estava na Taxa de Retorno Interno (TRI) veiculada pelo Governo Federal. O mercado não reagiu muito bem, os números publicados giravam em torno de $5,5 \%$ a $6 \%$, considerados muito baixos. Depois de meses de pressão (oito meses para ser mais exato), os investidores conseguiram fazer com que 0 Ministério da Fazenda elevasse a TRI para 7,2\% (FERNANDES, 2017) ${ }^{2}$.

De acordo com as premissas originárias, as concessões ocorreriam pelo critério de menor tarifa, não seria permitida a cobrança de pedágios em trechos urbanos das rodovias concedidas e a concessionária somente poderia cobrá-los a partir da conclusão de $10 \%$ da duplicação, o que significava que neste modelo não estava previsto o pagamento de outorga. Bem como, as concessionárias contratadas pelo Governo Federal realizariam a duplicação de $10 \%$ das rodovias, para depois cobrar as tarifas. Isto seria possível em decorrência da concessão patrocinada (FERNANDES, 2017).

No seu lançamento ( $1^{\circ}$ etapa do "PIL: rodovias"), explicitou-se a intenção de conceder dezenove trechos de rodovias federais, divididos em nove lotes. Em junho de 2015, a $2^{\text {a }}$ etapa do PIL foi publicada para o setor rodoviário. O carreamento de recursos públicos ficou estimado em $\mathrm{R} \$ 66,1$ bilhões de reais para os processos de descentralização que deveriam ocorrer entre 2015 e 2016. A previsão era conceder a iniciativa privada mais $\mathrm{km} 6.974$ de trechos rodoviários (seis trechos rodoviários) ${ }^{3}$. Nesta etapa, o Governo Federal já sinalizava para os setores empresariais que manteria a contraprestação pecuniária e continuaria a realizar os leilões com critério de menor tarifa, entretanto, flexibilizaria o prazo para a execução das obras de ampliação das rodovias e instalação dos serviços referentes à concessão. No total, as cifras anunciadas entre 2013 e 2017 somavam $R \$ 112$ bilhões.

Para o setor ferroviário estava previsto a construção e/ou melhoramentos de 11 mil quilômetros de ferrovias, para tal o governo e a pasta econômica ofereceram financiamento e empréstimos ao setor privado com carência de até cinco e

\footnotetext{
2 Este impasse foi responsável, por exemplo, por atrasos na realização das audiências públicas, na publicação de editais, no processo licitatório e na assinatura dos contratos. Essas etapas, segundo o cronograma inicial do governo, estavam previstas para acontecerem até julho de 2013. Assim, os primeiros editais foram publicados a partir de agosto de 2013 e o último contrato assinado em maio de 2015.

${ }^{3}$ O Governo também incluía e anunciava a concessão e os investimentos para BR-101/RJ (trecho da Ponte Rio-Niterói), que outrora compôs o Lote ํㅡ 1 da $1^{\text {a }}$ etapa do PIL.
} 
amortização num prazo de vinte e cinco anos. O cronograma de execução era de 30 anos, sendo que dos $R \$ 133$ bilhões de alavancagem inicialmente anunciadas, $68,4 \%$ dos recursos seriam para ferrovias.

O "PIL: ferrovias" seria instrumentalizado por meio de um novo modelo de concessão: o acesso aberto ou livre acesso (open access) e seria uma contrapartida sistema de integração vertical (vertical unbundling) vigente no país. Com tal pressuposto, o Programa em discussão, estava estruturado da seguinte forma:

1. O Governo contrataria a construção, manutenção e a operação da ferrovia através de concessão. A concessionária ficaria responsável pela instalação da infraestrutura, sinalização e pelo controle da circulação de trens (e demais equipamentos), detendo o direito de exploração da ferrovia;

2. A Valec ${ }^{4}$ compraria a capacidade integral da ferrovia (inclusive a ociosa);

3. A Valec faria a oferta pública da capacidade operacional. Desta maneira, assegurava o direito de passagem dos trens da malha ferroviária, objetivando a modicidade tarifária;

4. A Valec realizaria a venda da capacidade operacional da ferrovia, priorizando:

I. Operadores Ferroviários independentes;

II. Usuários que optassem por transportar carga própria;

III. Concessionários do setor (transporte) ferroviário.

5. A Valec remuneraria a concessionária por meio de Tarifa pela Disponibilidade da Capacidade Operacional (TDCO) ${ }^{5}$. Aqui seriam levados em consideração os investimentos realizados e os custos fixos de manutenção. O pagamento seria efetuado trimestralmente mesmo que não conseguisse subceder a capacidade que adquiriu, independentemente das condições de demanda; e

6. A concessionária prestaria serviços de operação diretamente aos usuários, que a remuneraria através de uma Tarifa de Fruição (TF), na medida houvesse utilização da ferrovia.

\footnotetext{
${ }^{4}$ Valec - Engenharia, Construções e Ferrovias S. A., esta é uma empresa pública, sob a forma de sociedade por ações, cujo vínculo com o Ministério dos Transportes está regido pela Lei $n^{\circ} 11.772$, de 17 de setembro de 2008.

5 Para a ANTT, capacidade operacional é "[...] capacidade de tráfego contratada da Ferrovia destinada à realização das atividades de transporte dos Usuários, expressa pela quantidade de trens que poderão circular, nos 2 (dois) sentidos, em um período de 24 (vinte e quatro) horas (Nota Técnica Conjunta no 001/SUFER-DCN/ANTT, 2013, p.04).
} 
Em outras palavras, neste modelo de outorga a Valec teria um papel preponderante, sua função no processo de contratação dos serviços era assumir o risco de demanda do concessionário (garantia ao parceiro privado de pagamento, independente da utilização efetiva do bem/serviço, isto é, do objeto do contrato). Comprando toda a capacidade, a empresa pública, ampliaria a participação de capital privado nos projetos de infraestrutura. Por outro lado, a Parceria PúblicoPrivada, ao transferir para a ferrovia ao particular, eliminaria o risco de engenharia por parte do Poder Público.

Bem como, com o anúncio da implantação do open access para o setor ferroviário, havia intenção de quebra de monopólios, quadro criado em decorrência da assinatura de contratos de concessão da década de 1990, sob tutela do Governo Fernando Henrique Cardoso (1995-2002).

A dinâmica do modelo vertical (vertical unbundling) e das concessões da década de 1990) de particulares não contribuiu para a modernização da malha ferroviária brasileira, pelo contrário impediu os fluxos de demanda. Nesse sentido, o modelo anunciado, por meio do PIL, abriria a possibilidade para o governo regular oferta e demanda de capacidade operacional por meio da Valec, ensejando a terceiros o direito de passagem e, sobretudo, atendendo anseios produtivos e comerciais. A intenção do governo era de que a intermediação da Valec, comprando e oferecendo a capacidade, fomentasse a estruturação de uma indústria nacional para os fins do setor.

\section{O Programa de Investimento em Logística: portos e aeroportos}

No caso dos portos, o PIL tinha como objetivo expandir e modernizar a infraestrutura e superestrutura portuária brasileira por meio de parcerias estratégicas com o setor privado. Para tal, o governo tinha a intenção de:

a) Retomar a capacidade de planejamento no setor portuário. Neste quesito o objetivo era:

I. Dotar de maior autonomia a Secretaria dos Portos da Presidência da República (SEP/PR) e conciliar suas funções com a atividade regulatória da Agência Nacional de Transportes Aquaviários (ANTAQ);

II. Criar do Instituto Nacional de Pesquisas Oceanográficas e Hidroviárias - INPOH. O órgão foi inaugurado em maio de 2013 e ficou incumbido de pensar ações de ampliação e melhoramento dos acessos aquaviários e terrestres; 
III. Integrar as autoridades dos portos (policial, fazendária, de saúde e marítima);

IV. Criar a Comissão Nacional das Autoridades nos Portos CONAPORTOS.

b) Aprimorar o marco regulatório para o setor portuário. Neste caso os escopos seriam:

I. Ampliar os arrendamentos no interior dos portos organizados, concessão de portos organizados e autorizações de Terminais de Uso Privativo (TUPs);

II. Extinguir a diferenciação para movimentação de carga própria e de terceiros;

III. Descentralizar sem a cobrar outorga, logo, as concessões dos portos e arrendamentos ocorreriam pelo critério de maior movimentação com menor tarifa e seriam realizadas chamadas/seleções públicas para autorizações de TUPs.

c) Realizar investimentos por meio de concessões, arrendamentos e

TUPs. Os valores anunciados para a primeira e segunda etapas do "PIL: portos" foram da ordem R \$ 91,6 para serem investidos entre os anos de 2014 e 2017. Para a execução dos projetos, os bancos públicos brasileiros poderiam financiar até $65 \%$ do valor do investimento.

Para atingir tais objetivos, o Governo editou a Medida Provisória ํㅡ. 595, de 6 de dezembro de 2012, convertida na Lei no. 12.815, de 5 de junho de 2013, que revogou a Lei no. 8.630/1993 (A Lei de Modernização dos Portos), estabelecendo-se assim um novo marco regulatório para o setor portuário brasileiro baseado "[...] na busca da modernização da gestão, ampliação da infraestrutura, atração de investimentos oriundos do setor privado e no aumento da movimentação de cargas com redução dos custos de operação e eliminação de barreiras comerciais" (FREZZA, 2016, p. 36).

A nova lei dos portos (Lei no. 12.815/2013) foi regulamentada pelo Decreto $\mathrm{n}^{\circ}$ 8.033, de 27 de junho de 2013, cujo artigo 9ำ foi modificado pelo Decreto no 8.464 e o artigo $62^{\circ}$ foi alterado pelo Decreto no 8.465, ambos de 8 de junho de 2015. As alterações dispostas no artigo 9 diziam respeito ao estabelecimento do critério de maior valor de outorga no julgamento de arrendamentos e concessões. Assim, a contratação passava a ser realizada sem outorga, via concessão patrocinada e via concessão comum. No que tange ao artigo $62^{\circ}$, as regras de arbitragem ficavam 
mais nítidas, sobretudo para dirimir litígios entre a União/entidades da administração pública federal indireta e iniciativa privada contratada em caso de inadimplência no recolhimento de tarifas portuárias ou outras obrigações financeiras frente a administração do porto e a ANTAQ.

Com o "PIL: aeroportos", o Governo Federal, tinha como objetivo melhorar a qualidade dos serviços e a infraestrutura aeroportuária, ampliar a oferta de transporte aéreo, sobretudo, por meio da instalação de uma rede de aviação regional. Portanto, as intenções eram:

a) Conceder os aeroportos de Galeão (RJ) e Confins (MG);

b) Instituir a Infraero Serviços (que seria uma subsidiária da Infraero). Aqui os objetivos seriam:

I. Estabelecer uma parceria com um operador internacional para ofertar serviços especializados de planejamento, administração, consultoria, treinamento de pessoal e outros relacionados à exploração de aeroportos no Brasil e no exterior;

II. Credenciar a nova estatal para operar em aeroportos fora da rede da Infraero;

III. Estabelecer uma academia de treinamento aeroportuário.

c) Estabelecer uma rede de aviação regional. Neste caso, era objetivo:

I. Criar o Programa de Desenvolvimento de Aviação Regional (PDAR);

II. Os projetos do PDAR teriam um aporte de $100 \%$ do Fundo Nacional de Aviação Civil (FNAC);

III. Ocorreriam também investimentos via Banco do Brasil, subsídios, isenções e parcerias com Estados e municípios;

IV. As descentralizações ocorreriam por meio de concessão administrativa e autorização:

a) Nas concessões administrativas, as despesas correntes da PPP seriam pagas integralmente pelo setor público caso o empreendimento não pudesse ser subsidiado por meio de tarifas ou pedágios,

b) As autorizações seriam utilizadas na construção de aeroportos para a aviação geral.

A previsão de investimentos por meio de concessões era na ordem de $\mathrm{R} \$$ 11,4 bilhões de reais, valor referente somente ao processo de descentralização dos aeroportos de Confins ( $R \$ 4,8$ bilhões) e Galeão ( $R \$ 6,6$ bilhões). Para a aviação regional estavam previstos $R \$ 15,8$ bilhões de reais referentes a $1^{\underline{a}}$ e $2^{\underline{a}}$ etapas do 
"PIL: aeroportos", a intenção era contemplar 270 aeroportos regionais em todas Unidades Federativas'. O objetivo geral era integrar o território nacional, promover o desenvolvimento dos polos regionais, fortalecer os centros de turismo e garantir acessos às comunidades da Amazônia Legal por meio da expansão da malha aeroportuária.

\section{Considerações Finais}

O PIL foi criado em meio à "guerra" do governo Dilma com os bancos por conta dos juros e spreads (no ano de 2012), teve suas primeiras ações (estudos técnicos, reuniões participativas, leilões, negociações com o setor privado no que tangia as concessões e empréstimos, etc.) realizadas em um contexto de crise política e econômica (isto é, em 2013, fim crescimento econômico proveniente da venda das commodities e de manifestações de rua, em 2014, ano de eleições presidenciais, de disputa pelos núcleos de poder do Estado e de unificação burguesa e no ano de 2015, momento de ajuste fiscal, manifestações de rua da alta classe média e preparação do falso impeachment) e foi extinto meses após o golpe de Estado. Logo que assumiu o Poder Executivo, Michel Temer, promoveu inúmeras mudanças. Em maio de 2016, o governo ainda interino, publicou a Medida Provisória nำ 727, que criou o Programa de Parcerias de Investimentos - PPI cuja intenção era celebrar contratos de descentralização para a execução de empreendimentos públicos de infraestrutura. A MP foi convertida na Lei $n^{0} 13.334$, de 13 de setembro de 2016.

No mesmo dia de conversão da lei, o novo governo anunciou um conjunto de concessões (trinta e quatro no total) com as regras do PPI sob a alcunha de "Projeto Crescer". Entre as mudanças mais contundentes estava o estabelecimento de um novo modelo de concessão com o pagamento de outorgas. Fora também anunciado que haveria mudança quanto ao modo de realizar os leilões. Novas condições financeiras foram estabelecidas, os Bancos Públicos (BNDES e CAIXA) repassariam o aporte público mediante os fluxos aferidos, o que significou redução da contraprestação pública, quebras de contratos e abandono do setor privado de inúmeros projetos previstos no PIL.

Através do Decreto nํ 8.875, de 11 de outubro de 2016, o governo Temer revogou o Decreto $n^{\circ}$ 8.129, de 23 de outubro de 2013, que instituiu a política de livre acesso (Open Access) ao sistema Ferroviário Federal e que dispunha, sobretudo, acerca da atuação da Valec - Engenharia, Construções e Ferrovias S.A, 
responsável pela compra, venda e oferta da capacidade integral da ferrovia (inclusive a ociosa) e remuneração das concessionárias por meio de Tarifa pela Disponibilidade da Capacidade Operacional (TDCO). O "PIL: ferrovias" efetivamente lançado em 2012 perdia sua concepção original e com tais reviravoltas nenhuma concessão para o setor ferroviário, concernente ao PIL ( $1^{\underline{a}}$ e $2^{\underline{a}}$ etapas), foi realizada.

Quanto ao setor aeroportuário, os aeroportos de Galeão (RJ) e Confins (MG) foram concedidos como o previsto. O financiamento a partir de $100 \%$ do FNAC para aviação regional não foi votado no congresso. Os debates ficaram em torno do impeachment (o golpe). Este ao ser concretizado modificou por completo as pretensões de investimentos para a aviação regional. Em agosto de 2016, Michel Temer, ainda como presidente interino, anunciou um corte de recursos que reduziu de 270 para 176 o número de investimentos previstos para os aeroportos regionais. O investimento que na época estava estimado em $\mathrm{R} \$ 7,3$ bilhões foi reduzido para $R \$ 2,4$ bilhões com previsão para ser realizado em 53 aeroportos até 2020.

Em relação ao "PIL: portos", as licitações e leilões para 2013 e 2014 não ocorreram como o previsto. Ao longo dos anos mencionados, acirradas discussões aconteceram acerca das regras jurídicas de contratação do particular. A resolução do impasse deu-se somente em junho de 2015. Este é o contexto da "greve de investimentos" dos empresários (SINGER, 2015) por conta da crise política. Até dezembro de 2016 nenhum dos portos organizados foi concedido e apenas três terminais portuários (instalações localizadas no interior dos portos organizados) haviam sido leiloados, sob a outorga na figura de arrendamentos (todos no porto de Santos). A previsão originária era de que entre os anos de 2013 e 2016 fossem arrendados quarenta e nove terminais.

No que diz respeito aos contratos de autorização para exploração de terminais fora das áreas dos portos organizados, igualmente, até o mês de dezembro de 2016 estavam habilitados (autorizados) para assinarem contratos 27 empreendimentos referentes aos Terminais de Uso Privativos - TUPs. Estes se somaram aos nove TUPs anteriormente construídos no âmbito do Programa de Investimento em Logística. Entretanto, a instalação dos equipamentos ocorreu no interior do PPI.

No que tange às concessões realizadas à iniciativa privada, referentes ao "PIL: rodovias", até o mês de fevereiro de 2017 haviam sido concedidas seis dos noves lotes originários relativos à 1 a etapa anunciada em agosto de 2012 . No interior da $2^{2}$ etapa, publicada em junho de 2015 , somente um trecho passou por processo 
de concessão: o segmento referente à ponte Rio-Niterói. É necessário destacar que o governo realizou as contratações do "PIL: rodovias" da $1^{\text {a }}$ etapa por meio de concessões patrocinadas.

Não era exatamente o que estava previsto nos cronogramas oficiais, contudo, deve-se entender que $o$ andamento dos processos referentes às etapas anunciadas no PIL foi influenciado pelo ambiente político construído por inúmeros agentes (cena política, empresários, mídia, judiciário, etc.) entre 2013 e 2016.

Isto inviabiliza uma avaliação mais aprofundada sobre os resultados do programa (projetados para 30 anos), sobretudo no que diz respeito ao modelo de descentralização (as PPPs). Como os projetos foram alterados, não há como julgar se tal relação era ou não viável. A PPP foi o instrumento escolhido para realizar os investimentos públicos e cobrar o cumprimento das metas da iniciativa privada e no âmbito nacional foi a primeira experiência realizada pelo governo federal.

Não foi nossa intenção realizar nesta discussão uma análise do modelo de parceria, mas as PPPs do PIL estavam atreladas ao um contexto macroeconômico neoliberal. Logo, a política desenvolvimentista pensada no segundo governo Dilma foi iniciada sem romper com o modelo. O PIL apresentou novas formas de concessão, no entanto, tais mecanismos são instrumentos neoliberais e acreditamos que caso o Golpe não tivesse ocorrido, as negociações com a iniciativa privada seriam demoradas e complexas, pois o regime jurídico, na prática era desconhecido e o setor empresarial teria que ter garantias plenas de que o governo arcaria com os projetos. Em outras palavras, o poder de convencimento teria que ser contundente, em especial para financiar projetos no setor ferroviário que sairiam do zero, bem como, os alinhamentos políticos bem definidos.

Entretanto, o Programa de Investimento em Logística (PIL) produziu algumas instituições. Entre as quais:

1) A Lei 12. 743, de 19 de dezembro de 2012 - Esta norma criou a Empresa de Planejamento e Logística (EPL). Embora o formato do PIL tenha sofrido inúmeras alterações, a estatal é um legado e cumpre suas funções. Foi a primeira a ação efetivamente produzida pelo Programa.

2) A Lei №. 12.815, de 5 de junho de 2013 - Aqui o Programa fundamentou novas regras para o setor portuário, num primeiro momento ratificou os processos de descentralização para o setor por meio do critério de menor tarifa, o que coincidia com as especificações da Lei 11.079/04 (Lei de PPPs), os contratos seriam de PPPs. 
3) A Lei no 13.097, de 19 de janeiro de 2015 - Esta lei criou o Programa de Desenvolvimento da Aviação Regional (PDAR). Ela não foi publicada como o governo desejava. A intenção era que o subsídio à aviação regional fosse concebido aos novos contratados do setor com recurso integral do FNAC, com a publicação de somente $30 \%$ deste será destinado à aviação regional.

4) O Plano Nacional de Logística Integrada (PNLI) - Em junho de 2015, A EPL publicou um relatório executivo com as principais diretrizes do PNLI. Atualmente a estatal está desenvolvendo estudos acerca dos projetos que vão efetivamente compor o plano. As regras criadas (e vigentes) com lançamento do PIL dão bases para o PNLI. Não existe muita informação sobre esta instituição que é uma consequência direta do Programa de Investimento em Logística. Está é uma questão que fica em aberta para estudos futuros.

Assim, a despeito das supracitadas instituições, é possível afirmar que o programa foi imensamente influenciado, atravessado e destruído pela condensação material e específica de uma relação de forças que culminou no Golpe, mas que também é uma resultante da própria articulação de classe do PT com determinada fração da burguesia brasileira. A rearticulação do bloco no poder entre 2013 e 2015 (BOITO JR, 2018), levou o governo Dilma a perder apoio das frações burguesas que iriam conduzir os projetos. Sem apoio destes, o PIL perdeu sustentação e o golpe de 2016 (que foi apoiado por parte da fração burguesa que apoiava os governos do PT) acabou por dar fim ao que havia sido projetado no programa.

\section{REFERÊNCIAS}

AGÊNCIA NACIONAL DOS TRANSPORTES TERRESTRES (ANTT). Nota Técnica Conjunta no 001/SUFER-DCN/ANTT. Programa de Investimentos em Logística - Ferrovias. Trecho Açailândia - Porto de Vila do Conde. Brasília, 2013.

AGÊNCIA NACIONAL DOS TRANSPORTES TERRESTRES (ANTT). Contrato de Concessão. EDITAL № 001/2013. Parte VII. Rodovia Federal: BR-050/GO/MG: trecho entre o entroncamento com a BR-040, em Goiás, até a divisa de Minas Gerais com o estado de São Paulo. Brasília, 2013. Disponível em:

<http://www.logisticabrasil.gov.br/rodovias3>. Acesso 03 jun. 2014.

AGÊNCIA NACIONAL DOS TRANSPORTES TERRESTRES (ANTT). Contrato de Concessão. EDITAL no 003/2013. Parte VII. Rodovia Federal: BR-163/MT: trecho de $\mathbf{8 5 0 , 9} \mathrm{km}$, sendo 822,8 km na BR-163/MT e 28,1 km na MT-407. Brasília, 2013. Disponível em: <http://www.logisticabrasil.gov.br/rodovias3>. Acesso 03 jun. 2014. 
Federal, até a divisa dos estados de Minas Gerais e São Paulo, e 546,30 km da BR 262, do entroncamento com a BR 153 ao entroncamento com a BR 381, no estado de Minas Gerais. Brasília, 2013. Disponível em: <http://www.logisticabrasil.gov.br/rodovias3>. Acesso 03 jun. 2014.

AGÊNCIA NACIONAL DOS TRANSPORTES TERRESTRES (ANTT). Contrato de Concessão. EDITAL no 005/2013. Parte VII. Rodovia Federal: BR-163/MS: trecho entre a divisa com o estado do Mato Grosso e a divisa com o Paraná. Brasília, 2013. Disponível em: <http://www.logisticabrasil.gov.br/rodovias3>. Acesso 04 mai. 2014.

AGÊNCIA NACIONAL DOS TRANSPORTES TERRESTRES (ANTT). Contrato de Concessão. EDITAL no 006/2013. Parte VII. Rodovia Federal: BR-040: trecho Brasília DF - Juiz de Fora - MG. Brasília, 2013. Disponível em: <http://www.logisticabrasil.gov.br/rodovias3>. Acesso 04 mai. 2014.

AGÊNCIA NACIONAL DOS TRANSPORTES TERRESTRES (ANTT). Contrato de Concessão. EDITAL no 001/2014. Parte VII. Rodovia Federal: BR-1531TOIGO: trecho de $624,8 \mathrm{~km}$ da rodovia BR-153, entre o entroncamento da BR-060 em Anápolis, no estado de Goiás, e o entroncamento com a TO-070 (Oeste) em Aliança do Tocantins. Brasília, 2014. Disponível em: <http://www.logisticabrasil.gov.br/rodovias3>. Acesso 04 out. 2014.

AGÊNCIA NACIONAL DOS TRANSPORTES TERRESTRES (ANTT). Contrato de Concessão. EDITAL no 005/2013. ANEXO II. PROGRAMA DE EXPLORAÇÃO DA RODOVIA (PER). BR-163/MS: Trecho da rodovia BR-163 integralmente inserido no estado do Mato Grosso do Sul, com extensão total de $847,20 \mathrm{~km}$ (início na divisa com o estado do Mato Grosso e término na divisa com o Paraná). Brasília, 2013. Disponível em: <http://www.logisticabrasil.gov.br/rodovias3>. Acesso 04 mai. 2014.

BARBOSA, F. O. Análise do arranjo institucional do setor portuário conforme a Lei no $12.815 / 2013$ e seus impactos na regulação de arrendamentos operacionais. Dissertação de mestrado - Universidade de Brasília. Faculdade de Tecnologia. Departamento de Engenharia Civil e Ambiental, Brasília, 2016.

BASTOS, P. P. Z. Ascensão e crise do governo Dilma Rousseff e o golpe de 2016: poder estrutural, contradição e ideologia, Rev. Econ. Contemp., núm. esp., p. 1-63, 2017.

BINENBOJM, G. As parcerias público-privadas (PPPs) e a Constituição, Revista Eletrônica de Direito Administrativo Econômico, Salvador, Instituto de Direito Público da Bahia, n. 2, maio-jun-jul, p. 159-175, 2005.

BOITO JR., A. Reforma e crise política no Brasil: os conflitos de classe nos governos do PT. Campinas/SP: Editora Unicamp/ São Paulo/SP: Editora Unesp, 2018.

BRAGA, V. \& CASTILLO, R. Tipologia e topologia de nós logísticos no território brasileiro: uma análise dos terminais ferroviários e das plataformas multimodais. Boletim Campineiro de Geografia, v. 3, n. 2, p. 235-258, 2013.

BRASIL. Presidência da República. Casa Civil. Subchefia para assuntos jurídicos. LEI № 11.079, de 15 de Agosto de 2004.

BRASIL. Presidência da República. Casa Civil. Subchefia para assuntos jurídicos. MEDIDA PROVISÓRIA № 576, de 19 de Agosto de 2012.

BRASIL. Presidência da República. Casa Civil. Subchefia para assuntos jurídicos. LEI № 12.815, de 5 de junho de 2013 (a). 
BRASIL. Presidência da República. Casa Civil. Subchefia para assuntos jurídicos. LEI № 8.987, de 13 de fevereiro de 1995.

BRASIL. Presidência da República. Casa Civil. Subchefia para assuntos jurídicos. DECRETO № 8.129, de 23 de outubro de 2013.

BRASIL. Presidência da República. Casa Civil. Subchefia para assuntos jurídicos. DECRETO № 8.134, de 28 de outubro de 2013.

BRASIL. Presidência da República. Casa Civil. Subchefia para assuntos jurídicos. DECRETO № 8.033, de 27 de junho de 2013 (b).

BRASIL. Presidência da República. Casa Civil. Subchefia para assuntos jurídicos. MEDIDA PROVISÓRIA № 652, de 25 de julho de 2014.

BRASIL. Presidência da República. Casa Civil. Subchefia para assuntos jurídicos. MEDIDA PROVISÓRIA № 656, de 07 de outubro de 2014.

BRASIL. Presidência da República. Casa Civil. Subchefia para assuntos jurídicos. DECRETO № 8.464, de 8 de junho de 2015.

BRASIL. Presidência da República. Casa Civil. Subchefia para assuntos jurídicos. DECRETO № 8.465, de 8 de junho 2015.

BRASIL. Presidência da República. Casa Civil. Subchefia para assuntos jurídicos. LEI № 13.097, de 09 de janeiro de 2015.

BRASIL. Presidência da República. Casa Civil. Subchefia para assuntos jurídicos. MEDIDA PROVISÓRIA № 727, 12 de maio de 2016.

BRASIL. Presidência da República. Casa Civil. Subchefia para assuntos jurídicos. LEI № 13.334, de 13 de setembro de 2016.

BRASIL. Presidência da República. Casa Civil. Subchefia para assuntos jurídicos. Decreto no 8.875, de 11 de outubro de 2016.

CARNEIRO, R. Navegando a contravento (Uma reflexão sobre o experimento desenvolvimentista do Governo Dilma Rousseff). Texto para Discussão. Unicamp. IE, Campinas, n. 289, mar., p. 1-40, 2017.

FARRANHA, A. C.; FREZZA, C. S.; BARBOSA, F. O. Nova lei dos portos: desafios jurídicos e perspectivas de investimentos. Rev. direito GV [online]. 2015, vol.11, n.1, p. 89-116, 2015.

FERNANDES, R. M. S. O PROGRAMA DE INVESTIMENTO EM LOGÍSTICA COMO INSTITUIÇÃO NO IMEDIATO: uma análise ("ao calor da hora") sobre a implantação de estratégias para o setor de transporte no Brasil e no Mato Grosso do Sul. Tese (Doutorado em Geografia) - Faculdade de Ciências Humanas, Universidade Federal da Grande Dourados, 2017.

FREZZA, C. S. A nova Lei dos Portos e os modelos de concessões e de agências reguladoras: mecanismos para a garantia do interesse público - Dissertação de Mestrado. Universidade de Brasília. Faculdade de Tecnologia. Departamento de Engenharia Civil e Ambiental, Brasília, 2016.

POULANTZAS, N. O Estado, o poder, o socialismo. 3ํe. ed. Rio de Janeiro- RJ. Brasil. Trad. Rita Lima, 2000. 
PRONER, C. et. al. A RESISTÊNCIA AO GOLPE de 2016. 1ª Edição. Bauru/SP: CANAL 6 editora, 2016.

RIBEIRO, M. P. (Org.). 10 Anos da Lei de PPP. 20 Anos da Lei de Concessões Viabilizando a Implantação e Melhoria de Infraestruturas para o Desenvolvimento Econômico-Social, 2014. Disponível em:< http://www.portugalribeiro.com.br/wpp/wpcontent/uploads/10-anos-lei-ppps-20anos-lei-concessoes.pdf>. Acesso em 12 fev. 2019.

SINGER, A. Cutucando a onça com varas curtas -

O ensaio desenvolvimentista no primeiro mandato de Dilma Rousseff (2011-2014). NOVOS ESTUDOS 102. Julho 2015.

\section{SOARES, R. P.; CAMPOS NETO, C. A. S. Das concessões rodoviárias às Parcerias} Público-Privadas: preocupações com o valor do pedágio. Brasília: Instituto de Pesquisa Econômica Aplicada (Ipea), 2006.

TV NBR. Ministro dos Transportes detalha o Programa de Investimentos em Logística: Rodovias e Ferrovias. Disponível em:<www.youtube.com./watch/atividadesdapresidenta/tvnbr>. Acesso em 18 set. 2012.

\section{NOTAS DE AUTOR}

\section{CONTRIBUIÇÃO DE AUTORIA}

Roberto Mauro da Silva Fernandes - Concepção. Coleta de dados, Análise de dados, Elaboração do manuscrito, revisão e aprovação da versão final do trabalho

\section{FINANCIAMENTO}

Este artigo é resultado de pesquisa doutoral e de pós-doutorado, assim gostaria de agradecer Coordenação de Aperfeiçoamento de Pessoal de Nível Superior - CAPES que concedeu financiamento em ambos os estágios, no âmbito do doutorado com bolsa demanda social CAPES, vinculado ao Programa de Pós-Graduação em Geografia da Universidade Federal da Grande Dourados e no pós-doutorado por meio ao Programa Nacional de Pós-Doutorado - PNPD, junto ao Programa de Pós-Graduação em Geografia da Universidade Estadual do centro-Oeste.

\section{CONSENTIMENTO DE USO DE IMAGEM}

Não se aplica

APROVAÇÃO DE COMITÊ DE ÉTICA EM PESQUISA

Não se aplica.

\section{CONFLITO DE INTERESSES}

Não se aplica.

\section{LICENÇA DE USO}

Este artigo está licenciado sob a Licença Creative Commons CC-BY. Com essa licença você pode compartilhar, adaptar, criar para qualquer fim, desde que atribua a autoria da obra.

\section{HISTÓRICO}

Recebido em: 24-06-2019

Aprovado em: 16-06-2020 